\title{
Association between Perceived Stress and Coping Strategies among Nurses in Intensive Care Units
}

\author{
Omaima Ezzat Mahmoud $^{1}$, Ragaa Dahi Mohamed ${ }^{2}$, Warda Ramadan Abouzied ${ }^{3}$, Donia Elsaid Fathi ${ }^{4} \&$ Reda $^{5}$ \\ Abd El Aal Thabet ${ }^{5}$ \\ 1. Assistant Professor of Psychiatric Mental Health Nursing, Faculty of Nursing, Beni- Suef University, Egypt \\ ${ }^{2 .}$ Lecturer of Critical Care and Emergency Nursing, Faculty of Nursing, South Valley University Qena, Egypt \\ ${ }^{3 .}$ Lecturer of Critical Care and Emergency Nursing, Faculty of Nursing, South Valley University Qena, Egypt \\ 4. Lecturer of Pediatric Nursing, Faculty of Nursing, PortSaid University, Egypt \\ 5. Assistant Professor of Psychiatric Health Nursing, Faculty of Nursing, Assiut University, Egypt
}

\begin{abstract}
Nurses are more susceptible to stress compared to other nurses and they are in need to use many coping strategies to help them to cope with stress. Aim: To investigate the association between perceived stress and coping strategies among nurses in intensive care units. Research Design: A descriptive research design was used in the current research. Setting: The study was applied in five intensive care units include the pediatric intensive care unit (ICU), general at Sohag University Hospital, and the obstetric critical care unit, general and pediatric intensive care unit at South-Valley University Hospital. Subjects: A convenient sample was used in this research which included all the nurses in the previously mentioned setting (70 nurses). Tools for data collection: Tool I: Self-administered questionnaire. Tool II: Perceived Stress Scale-10 (PSS-10) and Tool III: the Brief COPE Inventory. Results: The majority of the nurses reported a moderate stress level and one-quarter of them reported a severe level of stress. There was a highly statistically significant relationship between perceived stress and coping strategies in intensive care unit nurses. Conclusion: It was found that using a variety of coping strategies can be effective in reducing stress among nurses in intensive care units. Recommendation: Raising awareness and education of the nurses in intensive care units regarding coping strategies to help them cope with stress.
\end{abstract}

\section{Keywords: Nurses in the Intensive Care Unit, Coping Strategies \& Perceived Stress.}

\section{Introduction:}

Stress is considered any event, internal or environmental, that required adaptive and resistant resources among individuals or in the social systems. It involves organic and psychic changes which cause cognitive system interpretation by different stimuli. Coping strategies are used to deal with stressful situations. However, the absence of these strategies for neutralizing stressors may lead to the exacerbation of emotional exhaustion (Aiken et al., 2012).

Although nursing defined as a profession for about 50 years, it is considered one of the most stressful occupations. Stress in nursing has been reported widely and studied in different healthcare contexts, but it still needs further investigation by using different healthcare models and the management resources used in workplace strategies (Menzies, 2015).

Regarding ICUs, many studies have reported that nursing professionals who are working in this particular environment may deal with high levels of stress. Nurses daily are exposed to several adverse events, not only included the environment but also included the patients' critical condition, because working in such an environment, requires a quick decision- making which is a determining factor for patient care. It is strongly associated with neuroendocrine manifestations of stress (Hays et al., 2016).

In addition to this work include other characteristics indicated that nurses working in ICU represented a high prevalence of work-related exhaustion. Considering that stress in nursing is a reality and that the literature has not yet provided a clear definition of which factors are associated with them (Martins et al., 2015).

Nurses are faced multiple sources of stress related to work within a hospital setting including noise, load demands of work, interpersonal conflicts with other healthcare team personnel such as conflicts with physicians, role conflicts, dealing with death and dying, resources deficiency, lack of support from coworkers and supervisors, patient aggressiveness or violence, increasing patient loads, and challenging patients (Glazer \& Gyurak, 2018).

Healthcare professionals are at risk for psychological distress than others as a result of poor social support, poor psychosocial work environment, and many difficulties related to uncooperative patients are associated with stress among nurses. ICU nurses are experienced more stress levels than nurses worked in other units (McMeekin et al., 2017). 
Stress symptoms among healthcare professionals may increase the risk of depression. A very high level of stress can affect nurses' well-being and patient safety. So, ICU nurses try to use a variety of coping strategies to help them deal with stress. These strategies included cognitive, affective, and behavioral strategies (Hameed et al., 2018).

Cognitive strategies are included learning from experience, use verbalizing with others, and also, having group sessions while behavior strategies are included avoidance. Affective coping strategies is included having emotional support. However, Hampel \& Petermann, (2006) stated that coping is categorized into adaptive (effective) and maladaptive (ineffective) coping strategies (Al-Alawi et al., 2016). Adaptive behaviors are included talking it out, but maladaptive behaviors are involved avoidance, withdrawal, coming in late, calling in sick, and denial. Adaptive coping strategies are linked with less perceived stress. Maladaptive behavior is included self-blame, rumination, escape, or avoidance, which is linked with negative health consequences (Vinothkumar et al., 2016).

Stressors can harm most bodily systems. The negative effects are excessed with the working environment which leads to negative physical and psychological effects (Baigent \& Baigent, 2018).

\section{Significance of the study:}

Nurses are faced with a lot of demands that affected the professional and personal status of nurses and may increase the risk of stress and unhealthy behaviors (Ilhan et al., 2018). In addition to, the long work hours lead to feelings of nurses being overworked which may cause negative coping behaviors such as anger and other physical symptoms such as stomach pain, difficulty in sleeping, and headaches (Khubchandani \& Price, 2015).

\section{Research questions:}

1.What is the perceived stress level between intensive care unit nurses?

2.What are coping strategies were used between ICU nurses?

3.Is there a relationship between perceived stress and demographic characteristics between ICU nurses?

4.Is there a relationship between perceived stress and coping strategies between ICU nurses?

\section{Subjects and method \\ Aim of the study}

To investigate the association between perceived stress and coping strategies among nurses in intensive care units
Research design:

A descriptive research design was used in this research.

Setting:

The study was applied in five intensive care units include the pediatric intensive care unit and general at Sohag university hospital and the obstetric critical care unit, general and pediatric ICU at South-Valley University Hospital.

Subjects:-

The study subjects include a convenient sample that included all nurses in the previously mentioned setting (70 nurses) either male or female.

\section{Tools of data collection:}

Three tools were used for collecting data as follows:

Tool I: Self-administered questionnaire: it was developed by the researchers based on an extensive up-to-date literature review (McMeekin et al., 2017) which included 6 items related to demographic characteristics of nurses which are designed by the researchers as nurses' age, gender, educational level, years of experience, type of ICU, and hospital.

Tool II: Perceived Stress Scale-10 (PSS-10):

The Perceived Stress Scale-10 (PSS10) tool was adopted from Cohen et al., (1983) it consists of a tenitem self-report scale that examines individual stress levels. The nurses are asked to rate their feelings and thoughts during the past month. Each item was answered by the nurses on a five-point scale ranging from never (0) to very often (4). Therefore, each nurse's score ranged from 0 to 40 . Higher scores were indicated higher perceived stress levels.

\section{Scoring system:}

PSS scores between 0 and 13 were indicated lowstress level; 14-26 are indicated moderate stress, and 27 or above are indicated severe stress. Four items used reverse scoring (items 4, 5, 7, 8). Convergent validity was obtained through correlational analysis of the PSS with measures on anxiety, depression, helplessness, and disease activity. The scale internal consistency was 0.78 .

\section{Tool III: the Brief COPE Inventory.}

It was adopted from Carver, (1997). It was contained 28 items and has 14 subscales (2 items per subscale) that included various coping behaviors. Seven subscales (2 items each) are containing 14 items that are examined the effective coping strategies, which included active coping, instrumental support, and acceptance. The other seven subscales are examined ineffective coping behaviors, which are included self-distraction, denial, behavioral disengagement, and self-blame. The scale has been used widely in examining coping behaviors related to traumatic stressors. A previous report showed Cronbach's alpha from 0.50 to 0.90 among domains of the scale. 
$1=\mathrm{I}$ haven't been doing this at all

$2=$ I've been doing this a little bit

$3=$ I've been doing this a medium amount

4 = I've been doing this a lot

Scales are computed as follows (with no reversals of coding):

Self-distraction, items 1 and 19

Active coping, items 2 and 7

Denial, items 3 and 8

Substance use, items 4 and 11

Use of emotional support, items 5 and 15

Use of instrumental support, items 10 and 23

Behavioral disengagement, items 6 and 16

Venting, items 9 and 21

Positive reframing, items 12 and 17

Planning, items 14 and 25

Humor, items 18 and 28

Acceptance, items 20 and 24

Religion, items 22 and 27

Self-blame, items 13 and 26

1. I've been turning to work or other activities to take my mind off things.

2. I've been concentrating my efforts on doing something about the situation I'm in.

3. I've been saying to myself "this isn't real.".

4. I've been using alcohol or other drugs to make myself feel better.

5. I've been getting emotional support from others.

6. I've been giving up trying to deal with it.

7. I've been taking action to try to make the situation better.

8. I've been refusing to believe that it has happened.

9. I've been saying things to let my unpleasant feelings escape.

10. I've been getting help and advice from other people.

11. I've been using alcohol or other drugs to help me get through it.

12. I've been trying to see it in a different light, to make it seem more positive.

13. I've been criticizing myself.

14. I've been trying to come up with a strategy about what to do.

15. I've been getting comfort and understanding from someone.

16. I've been giving up the attempt to cope.

17. I've been looking for something good in what is happening.

18. I've been making jokes about it.

19. I've been doing something to think about it less, such as going to movies, watching TV, reading, daydreaming, sleeping, or shopping.

20. I've been accepting the reality of the fact that it has happened.

21. I've been expressing my negative feelings.
22. I've been trying to find comfort in my religion or spiritual beliefs.

23. I've been trying to get advice or help from other people about what to do.

24. I've been learning to live with it.

25 . I've been thinking hard about what steps to take.

26. I've been blaming myself for things that happened.

27. I've been praying or meditating.

28 . I've been making fun of the situation.

Scoring system:

Each item of this instrument was answered by the respondents using a 4-point Likert scale ranged from 1 (I have not been doing this at all) to 4 (I have been doing this a lot). Total scores for each subscale were calculated, and higher total subscale scores indicated greater perceived use of a corresponding coping behavior.

Validity and reliability of the tool:

Content validity: The content validity of the tools was tested by selected juries of critical care, psychiatric and pediatric nursing professionals to assess the clarity, feasibility, and applicability of the tools. Content validity index (CVI) was $88 \%$ for tool 1 . Internal consistency of reliability was measured using the alpha Cronbach test and R was 0.89 for tool 1 .

\section{Pilot study}

A pilot study was applied on $10 \%$ of nurses ( 7 nurses) to ensure and test the clarity and applicability of the tool. No modification in the tools was found. Nurses involved in the pilot were included in the current study.

\section{Procedure:}

After obtaining official permission, the researchers began to collect data from September 2020 to December 2020. The researchers have attended the previously selected settings of the study two days / a week from 9 am to 11 am. Data was collected from the studied nurses through a Self-administered questionnaire, Perceived Stress Scale, and Brief COPE Inventory. Each participant took about 20-30 minutes to fulfill the questionnaire. The researchers introduced themselves to the studied nurses; the purpose and importance of the study were explained. Oral consent was obtained from them before participation in the study. The researchers collected data from the nurses after completing the distributing questionnaire.

\section{Ethical considerations:}

Administrative permission was obtained from the heads of Sohag university hospital and South-Valley university hospital to collect data from the five units in the selected hospitals and the permission was sent to these units. Written informed consent from studied nurses was obtained. The study also followed ethical 
principles in clinical research and no harm for research subjects during the application of the study. Confidentiality was assured. Studied nurses had the right to refuse to share or withdraw from the study without giving any reason at any time.

\section{Statistical analysis}

The collected data were analyzed using Statistical Package for social sciences (SPSS) version 20. Data were computerized and presented using numbers, percentages. Mean and standard deviation were done for coping behaviors analysis among nurses and the $t-$ test, Pearson product correlation was used to investigate the relationship between stress and demographic data. A multiple regression analysis was done to investigate the effect of coping strategies on stress among nurses. A $\mathrm{P}$ value less than .05 was considered significant

\section{Results:}

Table (1): Distribution of the intensive care nurses according to their demographic characteristics $(\mathbf{n}=\mathbf{7 0})$

\begin{tabular}{|c|c|c|}
\hline Demographic characteristics & No. & $\%$ \\
\hline $\begin{array}{l}\text { Age (years) } \\
\quad \bullet<25 \\
\quad \bullet>25\end{array}$ & $\begin{array}{l}28 \\
42\end{array}$ & $\begin{array}{l}40.00 \\
60.00\end{array}$ \\
\hline Mean \pm SD. & \multicolumn{2}{|c|}{$27.26 \pm 3.06$} \\
\hline $\begin{array}{l}\text { Gender } \\
\text { - Male } \\
\text { - Female }\end{array}$ & $\begin{array}{l}17 \\
53\end{array}$ & $\begin{array}{l}24 \\
76\end{array}$ \\
\hline $\begin{array}{l}\text { Educational level } \\
\text { - Secondary nursing school } \\
\text { - Institute of nursing } \\
\text { - Faculty of nursing } \\
\end{array}$ & $\begin{array}{l}25 \\
23 \\
22 \\
\end{array}$ & $\begin{array}{l}35.0 \\
33.0 \\
32.0 \\
\end{array}$ \\
\hline $\begin{array}{l}\text { Years of experience } \\
\text { - Less than } 2 \text { years } \\
\text { - From } 2 \text { to } 6 \\
\text { - More than } 6 \text { years }\end{array}$ & $\begin{array}{c}18 \\
46 \\
6 \\
\end{array}$ & $\begin{array}{c}25 \\
66 \\
9\end{array}$ \\
\hline $\begin{array}{l}\text { Type of ICU } \\
\text { - Pediatric intensive care } \\
\text { - General intensive care } \\
\text { - Obstetric critical care unit }\end{array}$ & $\begin{array}{c}30 \\
31 \\
9\end{array}$ & $\begin{array}{l}43 \\
44 \\
13\end{array}$ \\
\hline $\begin{array}{l}\text { Hospital } \\
\text { - Sohag university hospital } \\
\text { - South-Valley university hospital. }\end{array}$ & $\begin{array}{l}25 \\
45\end{array}$ & $\begin{array}{l}36 \\
64\end{array}$ \\
\hline
\end{tabular}

Table (2): Distribution of the intensive care nurses according to their Perceived stress level $(n=70)$

\begin{tabular}{|l|c|c|c|c|}
\hline Perceived stress level & No. & \% & \multirow{3}{*}{} & \\
\hline$\bullet$ Low stress & 8 & 12 & \\
\hline$\bullet$ Moderate stress & 55 & 79 & & \\
\hline$\bullet$ Severe stress & 6 & 9 & & Maximum \\
\hline \multirow{2}{*}{ Overall Perceived stress } & Mean & SD & Minimum & 28.00 \\
\cline { 2 - 4 } & 18.61 & 2.56 & 9.00 & \\
\hline
\end{tabular}


Table (3): Distribution of the intensive care nurses regarding their coping strategies $(n=70)$

\begin{tabular}{|l|c|c|c|}
\hline \multicolumn{1}{|c|}{ Coping strategies } & Mean & SD & Minimum- Maximum \\
\hline$\bullet$ & 5.13 & 1.72 & $2.00-8.00$ \\
\hline$\bullet$ Self-distraction & 4.42 & 1.27 & $2.00-8.00$ \\
\hline$\bullet$ Actial & 5.85 & 1.65 & $2.00-8.00$ \\
\hline$\bullet$ Substance use & 1.12 & 0.74 & $2.00-7.00$ \\
\hline$\bullet$ Use of emotional support & 5.59 & 1.73 & $2.00-8.00$ \\
\hline$\bullet$ Use of instrumental support & 5.59 & 1.37 & $2.00-8.00$ \\
\hline$\bullet$ Behavioral disengagement & 4.02 & 1.82 & $2.00-8.00$ \\
\hline$\bullet$ Venting & 4.58 & 1.32 & $2.00-8.00$ \\
\hline$\bullet$ Positive reframing & 5.88 & 1.63 & $2.00-8.00$ \\
\hline$\bullet$ Planning & 5.48 & 1.34 & $2.00-8.00$ \\
\hline$\bullet$ Humor & 4.44 & 1.50 & $2.00-8.00$ \\
\hline$\bullet$ Acceptance & 5.64 & 1.62 & $2.00-8.00$ \\
\hline$\bullet$ Religion & 6.51 & 1.52 & 2.008 .00 \\
\hline$\bullet$ Self-blame & 3.76 & 1.27 & 2.007 .00 \\
\hline
\end{tabular}

Table 4: Association between perceived stress among intensive care nurses and their demographic characteristics

\begin{tabular}{|c|c|c|c|c|}
\hline Demographic characteristics & M & SD & Statistical test & p-value \\
\hline $\begin{array}{c}\text { Age (years) } \\
\quad<<25 \\
\bullet<25 \\
\end{array}$ & $\begin{array}{l}16.22 \\
17.68 \\
\end{array}$ & $\begin{array}{l}6.07 \\
3.54\end{array}$ & $r=-0.14$ & .063 \\
\hline \begin{tabular}{|l|} 
Gender \\
- Male \\
- Female \\
\end{tabular} & $\begin{array}{l}16.23 \\
17.45 \\
\end{array}$ & $\begin{array}{l}6.03 \\
3.24 \\
\end{array}$ & $\mathrm{t}=-0.58$ & 593 \\
\hline $\begin{array}{l}\text { Educational level } \\
\text { - Secondary nursing school } \\
\text { - Institute of nursing } \\
\text { - Faculty of nursing } \\
\end{array}$ & $\begin{array}{l}17.52 \\
17.65 \\
17.32 \\
\end{array}$ & $\begin{array}{l}3.18 \\
4.43 \\
3.23 \\
\end{array}$ & $t=-0.26$ & .806 \\
\hline $\begin{array}{l}\text { Years of experience } \\
\text { - Less than } 2 \text { years } \\
\text { - From } 2 \text { to } 6 \\
\text { - More than } 6 \text { years }\end{array}$ & $\begin{array}{l}17.75 \\
17.94 \\
17.50\end{array}$ & $\begin{array}{l}3.43 \\
4.26 \\
3.33\end{array}$ & $\mathrm{~F}=0.27$ & .805 \\
\hline $\begin{array}{l}\text { Type of ICU } \\
\text { - Pediatric intensive care } \\
\text { - General intensive care } \\
\text { - Obstetric critical care unit } \\
\end{array}$ & $\begin{array}{l}17.43 \\
18.20 \\
16.15\end{array}$ & $\begin{array}{l}3.28 \\
3.75 \\
3.23 \\
\end{array}$ & $\mathrm{~F}=3.49$ & .034 \\
\hline $\begin{array}{l}\text { Hospital } \\
\text { - Sohag university hospital } \\
\text { - South-Valley university hospital. }\end{array}$ & $\begin{array}{l}17.33 \\
18.23 \\
\end{array}$ & $\begin{array}{r}3.23 \\
4.13 \\
\end{array}$ & $\mathrm{t}=-0.93$ & .358 \\
\hline
\end{tabular}


Table (5): Association between perceived stress and coping strategies among nurses in the intensive care unit

\begin{tabular}{|l|c|c|c|c|c|c|c|}
\hline \multirow{2}{*}{ Predictor variables } & \multirow{2}{*}{$\boldsymbol{B}$} & \multirow{2}{*}{ SE-b } & \multirow{2}{*}{ Beta } & \multirow{2}{*}{ T } & \multirow{2}{*}{ P-value } & \multicolumn{2}{|c|}{ 95\% CI } \\
\cline { 6 - 8 } & & & & & Lower & Upper \\
\hline Self-distraction & 0.22 & 0.24 & 0.09 & 0.90 & .372 & -0.26 & 0.69 \\
\hline Active coping & -0.25 & 0.35 & -0.10 & -0.73 & .469 & -0.93 & 0.43 \\
\hline Denial & 0.66 & 0.39 & 0.25 & 1.72 & .087 & -0.10 & 1.43 \\
\hline Substance use & -0.78 & 0.42 & -0.17 & -1.84 & .068 & -1.62 & 0.06 \\
\hline Emotional support & -0.42 & 0.25 & -0.18 & -1.66 & .100 & -0.92 & 0.08 \\
\hline Use of instrumental & 0.11 & 0.34 & 0.04 & 0.32 & .753 & -0.57 & 0.78 \\
\hline Behavioral & 0.48 & 0.20 & 0.25 & 2.45 & .016 & 0.09 & 0.87 \\
\hline Venting & 0.11 & 0.30 & 0.04 & 0.37 & .713 & -0.48 & 0.70 \\
\hline Positive reframing & 0.28 & 0.32 & 0.13 & 0.87 & .385 & -0.35 & 0.90 \\
\hline Planning & 0.21 & 0.32 & 0.09 & 0.65 & .517 & -0.42 & 0.84 \\
\hline Humor & -0.34 & 0.27 & -0.16 & -1.25 & .212 & -0.87 & 0.20 \\
\hline Acceptance & -0.56 & 0.28 & -0.25 & -1.99 &. $\mathbf{0 4 8}$ & -1.12 & -0.01 \\
\hline Religion & -0.16 & 0.25 & -0.08 & -0.66 & .513 & -0.65 & 0.33 \\
\hline Self-blame & 0.88 & 0.24 & 0.32 & $\mathbf{3 . 6 5}$ & $<.001$ & 0.40 & 1.36 \\
\hline
\end{tabular}

Table (1): Showed distribution of intensive care nurses according to their characteristics. It was observed that less than two-thirds of nurses $(60 \%)$ their age $\geq 25$ years old and $75.3 \%$ of them were females. Regarding the educational level of nurses (35\%, $33 \%$, and $32 \%$ ), secondary nursing school, nursing institute, and nurses graduated from nursing college respectively. Concerning years of experience, more than half of the studied nurses $(60.0 \%)$ had 2-6 years of experience. According to the type of ICU, less than half of nurses worked in general ICU $(44.0 \%)$. As regards the hospital, $64 \%$ of nurses were worked in South-Valley university hospital and (36\%) of them in Sohag university hospital.

Table (2): Illustrated that majority of the intensive care nurses reported a moderate stress level experienced with only $12 \%$ of them had a low-stress level, six of the intensive care nurses stated a highstress level. Overall PSS mean score among the intensive care nurses was $18.61(\mathrm{SD}=2.56$, range $=9$ 28).

Table (3): Showed the coping strategies were used among intensive care nurses, it's observed from all items of the BCOPE that, religion was rating the commonly used coping strategies then positive reframing. Substance abuse was the lowest-rated dimension followed by self-blame.

Table (4): Revealed that significant differences were detected between the perceived stress among the intensive care unit nurses and types of intensive care unit. Also, revealed that intensive care nurses were working in general intensive care units stated highstress level than nurses were working in pediatric intensive care units. No association was noticed between the stress and the other demographic data.

Table (5): Illustrated the multiple regression model for all items was significant $(\mathrm{F}=3.65, \mathrm{P}=0$. 001).
Perceived stress was significantly affecting by behavioral disengagement, acceptance, and selfblame. an increasing found in the behavioral disengagement and self-blame scores corresponded to $0.48(\mathrm{P}=.016,95 \% \mathrm{CI}=0.09,0.87)$ and $0.88(\mathrm{P}<.001)$.

\section{Discussion:}

Stress and the ability to cope affect the health and performance of nurses at work. However, few studies are known about the effect of stress and coping adequacy and its effects on the nurses. This study aimed to investigate the association between perceived stress and coping strategies among nurses in the intensive care units.

The present study results revealed that more than three-quarters of nurses were females. These results are supported by a study conducted by Bogaert et al., (2017) about the effects of nurses' practice level at unit environment on nurse reported outcomes and found that the ICU nursing staff was presented in this study and the female gender was predominant. This is indicated that negative attitudes may have a positive effect on nurses and coping strategies for ICU nurses should be encouraged to develop to avoid stress.

The finding of the present study revealed that the majority of the intensive care nurses reported a moderate level of stress experienced with only more than ten percent of them reporting a low level of stress. This is indicated an overwork load that causes stress for nurses. These findings are in the same line with Santana et al., (2012), who found that most of the nurses their levels of stress at work rated in the "moderate" to "very high".

The present study indicated that there were several coping strategies were used among intensive care nurses, it's observed that religion was the most rated coping strategy than positive reframing. This is 
reflected the importance of religion in relieving stressors of life and help them to cope with those stressors. Substance abuse was the lowest-rated dimension followed by self-blame. These findings are matched with the study in Saudi Arabia conducted by Cruz et al., (2017) about spiritual care among nursing students and observed that religion is the most important topic in the world, may have relief, support, and strength all the people at difficult times.

Alotaibi et al, (2016) in their study about factors that may affect the nurses' job satisfaction in Saudi Arabian and recommended that facilities of health care should establish a spiritual climate among nurses to improve their perceptions. Cruz et al., (2017) stated that in their study about "Influence of religion and spiritual coping on human health that religion was rated as the common coping way during stressful situations and was effective means helps them to cope with stresses.

Similar findings are reported by McMeekin et al, (2017) that denial, self-blame, and self-distraction were common used among ICU nurses. Self-blame was the avoidance coping strategy used among ICU nurses which promotes helplessness in a stressful situation (Mróz, 2015).

The present study indicated that significant differences were detected between the perceived stress of the IC nurses and types of IC units. This is reflected in the difference in the type of intensive care unit that may be associated with differences in workload. These findings are in the line with the study done by Lorraine et al., (2010) and detected that in their study about stress, personality, and coping in IC nurses that coping ways may help ICU nurses in caring for patients. This reflected that ICU nurse's experience rather than general nursing experience is very important in the ICU.

These results are reliable with the finding of Vahedian-Azimi et al., (2017) about "Effects of Stress on ICU Nurses" and reported that there was a relation between the stress and the type of ICU. This may be related to several patients and over workload in ICU units than other units.

The findings of the present study revealed that a significant relation was detected between stress and coping strategies at $\mathrm{p}<0.001$. This is reflected the importance of coping strategies in nurses' life to help them cope with stressors. These findings are supported by the study conducted by Lambert et al., (2014) in Japan about comparing the workplace stressors, ways of coping and demographic characteristics and reported that health promotion programs for the effective workplace should be focused on stress management and stress reduction. Similarly, the study conducted in Jordan by Alhalaiqa \& Dweik, (2017) concluded in their study about Perceived stress in nurses that nurses stated that the score of ICU/CCU nurses stress levels was moderate level. Also, Oyeleye et al., (2013) conducted a study in the United States and stated that the score of stress was moderate among nurses in critical care nurses.

In contrast, the present findings are not in the line with Jones et al., (2013) who stated in their study in French about demographic and occupational factors of stress and fatigue intensive-care among registered nurses and nurses' aides that the stress among ICU nurses in France was low. This may be related to nursing workforce shortages, lack of emotional support from nursing supervisors, and salary is insufficient among ICU nurses.

\section{Conclusion:}

Depending upon the current study results and the research questions, which were concluded that the majority of nurses working in the intensive care reported that they experienced a moderate level of stress, with more than one ten parents reporting a low level of stress. Rating religion was the common coping strategy then positive reframing, active coping among nurses were working in the intensive care unit. There was a relationship between stress and demographic characteristics among nurses were working in the intensive care unit. There was a relationship was found between perceived stress among nurses were working in intensive care units and coping strategies.

\section{Recommendations:}

From the previous findings the following recommendations are suggested:-

Encourage coping strategies in the working environment to help create health and safe with reduced work-related stress. Nurse administrators can help the improvement of the working environment by formulating policies and procedures for their staff. Develop a plan for nurses that can improve their awareness about coping strategies and may minimize stress. Encourage nurses to exercise regularly, encourage nurses to eat healthily, foster better communication, start resilience training, promote self-awareness and emotional intelligence, organize social activities at work, and practice meditation.

\section{References:}

- Aiken LH, Sermeus W, Van den Heede K, Sloane DM, Busse R, \& McKee M. (2012): Patient safety, satisfaction, and quality of hospital care: cross-sectional surveys of nurses and patients in 12 countries in Europe and the United States. BMJ; 344:e1717. 
- Al-Alawi M, Al-Sinawi H, Al-Qubtan A, AlLawati J, Al-Habsi A, Al-Shuraiqi M, AlAdawi S, \& Panchatcharam SM. (2016): Prevalence and determinants of burnout Syndrome and Depression among medical students at Sultan Qaboos University: A cross-sectional analytical study from Oman. Arch Environ Occup Health; 8:1-10. Doi: 10.1080/19338244.2017.1400941.

- Alhalaiqa F, \& Dweik G. (2017): Perceived stress in nurses: A comparative study. Global J Health Sci; 9(6): 195-203.

- Alotaibi J, Paliadelis PS, \& Valenzuela FR. (2016): Factors that affect the job satisfaction of Saudi Arabian nurses. J Nurs Manag, Apr; 24(3):275-82. Doi: 10.1111/jonm.12327.

- Baigent M, \& Baigent R. (2018): Burnout in the medical profession: not a rite of passage. Med J Aust; 208(11):471-472.

- Bogaert PV, Clarke S, Roelant E, MeulemanS H, \& Heyning PV. (2017): Impacts of unit-level nurse practice environment and burnout on nurse reported outcomes: a multilevel modeling approach. J Clin Nurs; 19(11-12):1664-74.

- Carver CS. (1997): You want to measure coping but your protocol's too long. Consider the Brief COPE. Int J Behav Med; 4 (1): 92-100

- Cohen S, Kamarck T, \& Mermelstein R. (1983): A global measure of perceived stress. J Health Soc Behav; 24 (4): 385-396. Doi: 10. 2307/2136404, PMID 6668417

- Cruz JP, Alshammari F, Alotaibi KA, \& Colet PC. (2017): Spirituality and spiritual care perspectives among baccalaureate nursing students in Saudi Arabia: A cross-sectional study. Nurse Educ Today; 49: 156-162.

- Cruz JP, Colet PC, Alquwez N, Inocian EP, Al?Otaibi RS, \& Islam SMS. (2017): Influence of religiosity and spiritual coping on health? related quality of life in Saudi hemodialysis patients. Hemodial Int; 21(1): 125-132.

- Glazer S, \& Gyurak A. (2018): "Sources of occupational stress among nurses in five countries", International Journal of Intercultural Relations, vol. 32, no. 1, pp. 49-66.

- Hameed TK, Masuadi E, Al Asmary NA, AlAnzi FG, \& Al Dubayee MS. (2018): A study of resident duty hours and burnout in a sample of Saudi residents. BMC Med Educ; 18(1):180. Doi: 10.1186/s12909-018-1300-5.

- Hampel P, \& Petermann F. (2006): Perceived stress, coping, and adjustment in adolescents. J Adolesc Healthcare; 38(4): 409-415.

- Hays MA, All AC, Mannahan C, Cuaderes E, \& Wallace D. (2016): Reported stressors and ways of coping utilized by intensive care unit nurses. Dimens Crit Care Nurs; 25(4):185-93.
- Ilhan, E. Durukan, E. Taner, I. Maral, M. \& Bumin. A (2018): "Burnout and its correlates among nursing staff: questionnaire survey," Journal of Advanced Nursing, vol. 61, no. 1, pp. 100-106.

- Jones G, Hocine M, Salomon J, Dab W, \& Temime L. (2013): Demographic and occupational predictors of stress and fatigue in French intensive-care registered nurses and nurses' aides: A cross-sectional study. Int J Nurs Stud; 52(1): 250-259.

- Khubchandani \& Price J. H. (2015): "Workplace harassment and morbidity among US adults: results from the National Health Interview Survey," Journal of Community Health, vol. 40, no. 3, pp. 555-563.

- Lambert, C. Lambert, E. \& Itano J. (2014): Cross-cultural comparison of workplace stressors, ways of coping and demographic characteristics as predictors of physical and mental health among hospital nurses in Japan, Thailand, South Korea and the USA (Hawaii)," International Journal of Nursing Studies, vol. 41, no. 6, pp. 671-684.

- Lorraine B, Fiona I \& Akhtar W. (2010): Personality, stress and coping in intensive care nurses: a descriptive exploratory study, The Authors. Journal Compilation (C) 2010 British Association of Critical Care Nurses, Nursing in Critical Care $\bullet$ Vol 15 No 3

- Martins JT, Robazzi MLCC, \& Bobroff MCC. (2015): Pleasure and suffering in the nursing group: reflection to the light of Dejour psychodynamics. Rev Esc Enferm USP [Internet]. [cited Aug 03]; 44(4):1107-11. Available from: http://www.scielo.br/pdf/reeusp/v44n4/en_ 36.pdf

- McMeekin DE, Hickman RL, Douglas SL, \& Kelley CG. (2017): Stress and coping of critical care nurses after unsuccessful cardiopulmonary resuscitation. Am J Crit Care; 26(2): 128-135.

- Menzies IEP. (2015): Nurses under stress. Int Nurs Rev; 7(6): 9-16. 6. Bianchi ERF. Enfermeiro hospitalar stress. Rev Esc Enferm USP [Internet]. [citado ago. 03]; 34(4):390-4. Disponível em: http://www.scielo.br/pdf/reeusp/v34n4/v34n4a11. pdf

- Mróz J. (2015): Predictive roles of coping and resilience for the perceived stress in nurses. Prog Health Sci; 5(2):77-83.

- Oyeleye O, Hanson P, O'Connor N, \& Dunn D. (2013): Relationship of workplace incivility, stress, and burnout on nurses' turnover intentions and psychological empowerment. J Nurs Adm; 43(10): 536-542

- Santana JCB, Sousa MA, Soares HC, \& Avelino KSA. (2012): Factors influence and 
minimize of errors an administration de medicaments pela equip de enfermagem. Enferm Rev; 15(1):122-37

- Vahedian-Azimi A, Hajiesmaeili M, Kangasniemi M, Fornés-Vives J, Hunsucker RL, \& Rahimibashar, F, (2017): Effects of Stress on Critical Care Nurses: A National CrossSectional Study. J Intensive Care Med. Doi: 10.1177/0885066617696853.

- Vinothkumar M, Arathi A, Joseph M, Nayana P, Jishma EJ, \& Sahana U. (2016): Coping, perceived stress, and job satisfaction among medical interns: The mediating effect of mindfulness. Ind Psychiatry J; 25(2): 195-201. doi:10.4103/ipj.ipj_98_14 